\title{
Bacteriological Profile of the Organisms Causing Septicaemia and their Antibiotic Resistance Patterns
}

\author{
V. Deepali and R. Shyamala* \\ Department of Microbiology, MRMCW, Hyderabad, India \\ *Corresponding author
}

\section{A B S T R A C T}

\begin{tabular}{|l|}
\hline K e y w o r d s \\
$\begin{array}{l}\text { Bacteriological } \\
\text { profile, Organisms, } \\
\text { septicaemia, } \\
\text { Antibiotic resistance } \\
\text { patterns, Therapy }\end{array}$ \\
\hline Article Info \\
\hline $\begin{array}{l}\text { Accepted: } \\
\text { 15 July 2019 } \\
\text { Available Online: } \\
\text { 10 August } 2019\end{array}$ \\
\hline
\end{tabular}

Blood stream infections are mainly caused by multi drug resistant organisms which more likely prolong the hospital stay and leads to increased health care costs. Hence, early diagnosis and treatment with appropriate antibiotics is the only way to treat bacteraemia. To study the bacteriological profile of the organisms causing septicaemia and their antibiotic resistance patterns to guide the clinicians to initiate the empirical therapy. Blood samples were collected aseptically from patients before taking any antibiotics. Samples were inoculated into Brain heart infusion broth and incubated at 37 degree for 24 hours. Blind subculture was done on to fresh 5\% sheep blood agar and MacConkey agar. A negative result was followed up by examining the broth daily and doing a final subculture at the end of $7^{\text {th }}$ day organisms identified by colony morphology and standard biochemical tests. A total of 273 blood samples were analysed, out of which 50 yielded growths (18.3\%). Among this, $49(98 \%)$ yielded bacterial isolates and $1(2 \%)$ was Candida species. Out of 49 bacterial isolates, $28(56 \%)$ were Gram positive organisms and 21 (42\%) were Gram negative organisms. Among Gram positive isolates Coagulase negative Staphylococci $(36 \%)$ were the predominant isolates. Among the Gram negative organisms, Escherichia coli $(22 \%)$ were the predominant isolate. The incidence of blood stream infection was $18.3 \%$. Majority were bacterial isolates. Gram positive were more than gram negative. Among Gram positive isolates. Coagulase negative Staphylococci (36\%) were the predominant isolates. Among the Gram negative organisms, Escherichia coli (22\%) was the predominant isolate

\section{Introduction}

In the hospital patients, deaths and morbidities are most commonly caused by septicemias. There are many diseases that are associated with the infections of the origin of the health care. But among them all, septicemias are the most common infections. These infections can be sometimes mild and they are self-limiting. But sometimes they are life threatening and require immediate attention and appropriate treatment. The treatment must be rapid. Septicemia can be caused by a variety of microorganisms. The causative organisms depend upon the area to area. The case fatality rate can reach up to $100 \%$ if the patient is not treated properly (Atul et al., 2007). Broadly organisms causing health care associated septicemias can be classified as gram positive and gram negative. Death rate of infections caused by gram negative organisms is more compared to death rate of infections caused by gram positive organisms. Septicemia problem is compounded by increasing resistance to antibiotics commonly used in the hospital practice. It leads to increased morbidity and 
mortality and patient needs to stay for prolonged periods of time in the hospital. This leads to increased costs of the health care (Gangoue et al., 2006).

In some cases, it becomes very difficult to achieve the cure rates due to infection caused by resistance of the causative organisms added with colonization. The therapeutic options are reduced in such cases. This leads to difficulty in treatment of the cases (Collignon, 2002).

A variety of reasons are listed for the above mentioned problems. The most common reason is the increasing use of the antibiotics followed by improper use not only in human beings but also in animals and other places. Improper control of the infection, overcrowding etc can also be treated as the reasons for this. In patients with septicemia, as there are increased chances of the deaths and diseases, it is a common strategy that the patient is treated as per the clinical decision with antibiotics i.e. empirical treatment. The blood is sent for culture and sensitivity. Once the results come, the patient is treated as per it (Kholy et al., 2009).

The empirical treatment is based on the certain factors like pattern of the resistance to the antibiotics locally based on previous experiences of the local area. This has to be done before the availability of the reports which becomes available after the culture and sensitivity. Septicemia is caused by a variety of the microorganisms and their sensitivity pattern also varies. But the diagnosis must be very prompt and aggressive treatment has to be given to save the life of the patient (Adejuyigbe et al., 2001).

In most cases of suspected septicemia antimicrobial therapy is always initiated empirically because bacteriological culture results take about a week to be available (Adejuyigbe et al., 2001).
The present study was undertaken to study the bacteriological profile of the organisms causing septicaemia and their antibiotic resistance patterns to guide the clinicians to initiate the empirical therapy.

\section{Materials and Methods}

\section{Study design}

Hospital based retrospective study

\section{Place of the study}

Present study was carried out in the department of Microbiology, Malla Reddy Medical College for Women, Hyderabad

\section{Study period}

Present study was carried out from November 2018 to April 2019.

\section{Sample size}

A total of 273 blood samples from clinically suspected cases of bacteraemia were studied.

A total of 273 blood samples from clinically suspected cases of bacteraemia were studied.

This study is a retrospective observational study conducted in the department of microbiology laboratory for a period of 6 months from November 2018 to April 2019.

Blood samples were collected aseptically from patients before taking any antibiotics. Samples were inoculated into Brain heart infusion broth and incubated at 37 degree for 24 hours. Blind subculture was done on to fresh $5 \%$ sheep blood agar and MacConkey agar. A negative result was followed up by examining the broth daily and doing a final subculture at the end of $7^{\text {th }}$ day organisms identified by colony morphology and standard biochemical tests. 
Antibiotic susceptibility testing was performed by Kirby Bauer's disc diffusion method according to CLSI guidelines.

\section{Statistical analysis}

The data was entered in the Microsoft Excel worksheet and was analyzed using proportions.

\section{Results and Discussion}

A total of 273 blood samples were analysed, out of which 50 yielded growths (Table 1).

Among 50 positive blood culture samples, $49(98 \%)$ yielded bacterial isolates and $1(2 \%)$ was Candida species. Out of 49 bacterial isolates, $28(56 \%)$ were Gram positive organisms and $21(42 \%)$ were Gram negative organisms. Among Gram positive isolates Coagulase negative staphylococci $(36 \%)$ were the predominant isolates followed by Staphylococcus aureus (14\%) and Enterococcus species (4\%) (Figure 1).

Among the total S. aureus isolates MRSA was found to be in $14.3 \%$ whereas MRCONS was found in $21.4 \%$ of total CONS isolates.

Among the Gram negative organisms, Escherichia coli (22\%) was the predominant isolate followed by Klebsiella sp (14\%) (Figure 2).
During the study period we did not observe any Polymicrobial growth.

The present study shows the sensitivity pattern of Gram positive isolates towards various antibiotics. Among the Gram positive isolates, most of the isolates showed resistance to penicillin, erythromycin, and clindamycin, azithromycin followed by cotrimoxazole, doxycycline and ciprofloxacin. None of the isolates exhibited resistance to Vancomycin, Teicoplanin and linezolid. Among the Gram negative isolates, majority of the isolates were resistant to Beta lactam antibiotics, followed by Amoxyclav, cotrimoxazole, fluoroquinolones and amino glycosides. Majority of the isolates showed least resistance to Carbapenems and Tigecycline. Enterobacteriaceae showed high sensitivity to cefoperazone/sulbactam combination (90.4\%). None of the isolates showed resistance to colistin and polymyxin (Table 2).

In the present study, a total of 273 blood samples were analysed, out of which 50 yielded growths (18.3\%). Among this, 49 (98\%) yielded bacterial isolates and $1(2 \%)$ was Candida species. Out of 49 bacterial isolates, $28(56 \%)$ were Gram positive organisms and $21(42 \%)$ were Gram negative organisms. Among Gram positive isolates Coagulase negative staphylococci (36\%) were the predominant isolates. Among the Gram negative organisms, Escherichia Coli (22\%) were the predominant isolate.

Table.1 Overall adult and paediatrics blood culture results

\begin{tabular}{|l|c|c|c|}
\hline Result & Adults (\%) & Paediatrics (\%) & Total (\%) \\
\hline Growth & 42 & 8 & 50 \\
\hline No growth & 190 & 33 & 223 \\
\hline Total & 232 & 41 & 273 \\
\hline
\end{tabular}


Table.2 Antibiotic sensitivity patterns of Gram negative bacilli

\begin{tabular}{|l|l|l|}
\hline Antibiotics & $\begin{array}{l}\text { E. Coli and } \\
\text { Klebsiella }\end{array}$ & Other GNB \\
\hline Ampicillin & $2(18.2)$ & $2(66.6 \%)$ \\
\hline Amoxyclav & 0 & 0 \\
\hline Cefepime & $10(55.5 \%)$ & $3(100 \%)$ \\
\hline Ceftazidime & $7(39 \%)$ & $3(100 \%)$ \\
\hline Cefuroxime & $7(39 \%)$ & $2(66.6 \%)$ \\
\hline $\begin{array}{l}\text { Piperacillin } \\
\text { tazobactum }\end{array}$ & $16(82 \%)$ & $3(100 \%)$ \\
\hline $\begin{array}{l}\text { Cefoperazone- } \\
\text { sulbactum }\end{array}$ & $18(100)$ & $3(100 \%)$ \\
\hline Gentamicin & $10(55.5 \%)$ & $2(66.6 \%)$ \\
\hline Amikacin & $10(55.5 \%)$ & $2(66.6 \%)$ \\
\hline Imipenem & $10(94.4 \%)$ & $3(100 \%)$ \\
\hline Meropenem & $17(94.4 \%)$ & $3(100 \%)$ \\
\hline Ciprofloxacin & $15(83.3 \%)$ & $2((66.7)$ \\
\hline Polymyxin & $18(100)$ & $3(100 \%)$ \\
\hline Colistin & $18(100)$ & $3(100 \%)$ \\
\hline Tigecycline & $18(100)$ & $3(100 \%)$ \\
\hline
\end{tabular}

Fig.1 Distribution of Gram positive cocci

\section{Bacterial Etiology}

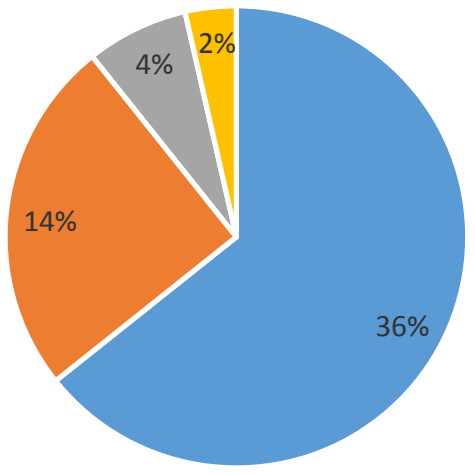

- CONS Staphaureus Enterococcus - OTHERS 
Fig.2 Distribution of Gram negative bacilli

$10 \%$

$22 \%$

E.Coli Klebsiella spp Citrobacter spp Pseudomonas aeruginosa

Sravan Reddy et al., (2018) found that the incidence of blood stream infection was seen in 22 out of 75 patients studied (Sravan Reddy et al., 2018). Most commonly affected age group was 31-45 years. Gram positive isolates were more than gram negative isolates and this finding was similar to the finding of the present study. Among the gram-positive bacteria, majority isolated were S. epidermidis; followed by S. aureus, but we found that Among Gram positive isolates Coagulase negative staphylococci $(36 \%)$ were the predominant isolates.

Anjum et al., (2019) noted that the incidence of the blood stream infection was $36.6 \%$ which was double than that observed in the present study (Anjum et al., 2019). Gram positive isolates were more than gram negative isolates and this finding was similar to the finding of the present study. Among gram-positive bacteria, predominant isolates were Coagulase Negative Staphylococcus (41\%) and this finding was similar to the finding of the present study. Among gramnegative isolates, 14\% were Pseudomonas sp.but we found that Among the Gram negative organisms, Escherichia coli (22\%) were the predominant isolate.

Garg et al., (2007) observed that the incidence of the blood stream infection was $20.5 \%$ and this finding was similar to the finding of the present study (Garg et al., 2007). They found that gram negative bacteria incidence was more than that of the gram positive bacteria but we found that Gram positive isolates were more than gram negative isolates. Pseudomonas spp. (16\%) was common in the gram negative but we found that Among the Gram negative organisms, Escherichia coli (22\%) were the predominant isolate. Staphylococcus aureus (8.3\%) was the predominant isolate in gram positive cases, and this finding was similar to the finding of the present study.

Pandey et al., (2017) found that the incidence of blood stream infection was $30.6 \%$ which was almost double than that observed in the present study (Pandey et al., 2017). They found that gram negative bacteria incidence was more than that of the gram positive bacteria but we found that Gram positive 
isolates were more than gram negative isolates. Klebsiella sp (23\%) was common in gram negative cases but we found that Among the Gram negative organisms, Escherichia coli $(22 \%)$ were the predominant isolate. Enterococci (20\%) were the predominant isolate in gram positive cases but we found that Among Gram positive isolates Coagulase negative Staphylococci (36\%) were the predominant isolates.

Kamga et al., (2011) found that the incidence of blood stream infection was $28.3 \%$ which was more than that observed in the present study (Kamga et al., 2011). They observed that the children were the most commonly affected but we found that age group of 31-40 years was the most commonly affected in the present study. Gram positive isolates were more than gram negative isolates and this finding was similar to the finding of the present study. Among the gram-positive bacteria, 52 (82.5\%) were Staphylococciand this finding was similar to the finding of the present study.

The incidence of blood stream infection was $18.3 \%$. Majority were bacterial isolates. Gram positive were more than gram negative. Among Gram positive isolates. Coagulase negative staphylococci (36\%) were the predominant isolates. Among the Gram negative organisms, Escherichia coli (22\%) was the predominant isolate

\section{References}

Adejuyigbe EA, Adeodu OO, Ako NK, Taiwo O, Owa JA. Septicemia in High Risk Neonates at a Teaching Hospital in Ile Ife. East. Afr Med J. 2001; 789: 590-3.

Anjum N, Umesh, Rawat V, Kumar M, Deopa MS. Comparative study on conventional blood culture and automated blood culture (bactec 9050) in the early detection of bacterial isolates in tertiary care hospital of Kumaun region. J. Evolution Med. Dent. Sci. 2019; 8(20): 1647

Atul G, Anupuba S, Taya G, Goyal RK, Sen MR. Bacteriological Profile and Antimicrobial Resistance of Blood Culture Isolate from a University Hospital. J Indian Acad Clin Med 2007; 8(2)139-43.

Collignon PJ. Antibiotic Resistance. Med J Aust 2002; 177(6): 325-9.

Gangoue PJ, Sinata KS, Ngassam P, Adiago

D, Ndumbe P. Antimicrobial Activity Against Gram-Negative Bacilli from Yaounde Central Hospital, Cameroon. Afr Health Sci 2006; 6(4) 232-235.

Garg A, Anupurba S, Garg J, Goyal RK, Sen MR. Bacteriological Profile and Antimicrobial Resistance of Blood Culture Isolates from a University Hospital. J Indian Acad Clin Med 2007; 8(2): 139-43

Kamga HLF, Njunda AL, Nde PF, Assob JCN, Nsagha DS, Weledji P. Prevalence of septicemia and antibiotic sensitivity pattern of Bacterial isolates at the university teaching hospital, yaoundé, Cameroon. Afr J Clin Experimental Microbiol 2011; 12(1): 2-8

Kholy A, Baseem H, Hall GS, Procop GW, Longworth DL. Antimicrobial Resistance in Cairo, Egypt 1999-2000: a survey of five hospitals. J Antimicrob Chemother 2003; 51(3): 625-30.

Pandey M, Nirnajan D, Pande RC. Bacteriological Profile and Antimicrobial Resistance of Blood Culture Isolates from a 350 bedded Hospital Lucknow, India Int J Curr Microbiol App Sci 2017; 6(1): 184-193

Sravan Reddy K. A Prospective Study on Incidence of Septicemia in patients in IPD of Medicine Department. Int Arch Biomed Clin Res 2018; 4(2): 190-192 


\section{How to cite this article:}

Deepali, V. and Shyamala, R. 2019. Bacteriological Profile of the Organisms Causing Septicaemia and their Antibiotic Resistance Patterns. Int.J.Curr.Microbiol.App.Sci. 8(08): 1747-1753. doi: https://doi.org/10.20546/ijcmas.2019.808.206 